\author{
Transparency and quality control are essential in the highly uncertain business of assessing the impact \\ of climate change on a regional scale.
}

$\mathrm{C}$ limate scientists are engaged in a lively debate about how — or whether - the Intergovernmental Panel on Climate Change (IPCC) should reform itself (see Nature 463, 730-732; 2010). At a minimum, the panel needs to hold itself to the highest possible standards of quality control in future assessments.

But so do climate scientists themselves - especially those who study the links between global climate change and its potential regional effects on factors such as weather patterns, ecosystems and agriculture. Governments faced with the need to make difficult, disruptive and politically fraught decisions about when and how to respond to climate change are understandably eager for certainty. But certainty is what current-generation regional studies cannot yet provide. Researchers need to resist the pressures to overstate the robustness of their conclusions, and to be as open as possible about where the uncertainties lie.

As an example of the scientific challenges involved, imagine a regional authority wanting to plan for water resources in a river basin over the next four decades. An applicable study might be probabilistic in approach. It could take into account a range of global greenhousegas-emission trajectories, and involve multiple runs of global climate models using different values for a number of parameters. However, such models cannot reproduce some important atmospheric phenomena such as circulation trapping, and cannot be validated against real climate behaviour over decadal timescales. The multiple runs will produce a probability distribution of precipitation which itself will contain intrinsic uncertainties. These outcomes then need to be fed into a catchment model with its own range of parameters and limitations of knowledge, and which in turn needs to be coupled to models of water demand as local housing and populations change over the period (M. New et al. Phil. Trans. R. Soc. A 365, 2117-2131; 2007, and other papers in that issue).

Climate projections at the national level are crucial for such efforts. One such study was published last year, when the UK Met Office

produced its climate projections of the next eight decades, including analysis down to a resolution of 25-kilometre squares (http:// ukclimateprojections.defra.gov.uk). The British government is now conducting a national climate-change risk assessment, due for completion in early 2012, that uses the projections. But such an application could well be problematic: it is likely that the projections reflect the limitations of the models and analyses as much as probabilities intrinsic to the real world. Yet regional planners and others might easily miss the detailed discussions of uncertainties, and misguidedly seize on these projections as a solid basis for investment decisions. And depressingly for decision-makers, the more the uncertainties are explored, the greater the ranges in the projected possible outcomes are likely to become.

This combination of projections and risk analysis is one way in which an over-reliance by decision-makers on modelling may be setting up the scientific community for a loss of trust. What is more, like regional-impact studies,

"Grey-literature studies should be transparently peer reviewed as a part of their commission." such analyses often appear not in peer-reviewed journals but in 'the grey literature' - in reports, or on websites. Yet they are no less important in representing the outputs of climate science, and need to be included in the IPCC assessment. For these reasons, such grey studies should be transparently peer reviewed as a part of their commission.

Uncertainties about future climate effects do not undermine the case for action to reduce greenhouse-gas emissions. But there is a long way to go in the science before regional-impact studies provide a suitable basis for detailed planning. Whatever the pressures, statements by scientists and government agencies about such studies need to be well qualified, and policies based on them need to be kept as flexible as possible. It is intrinsic to this research, after all, that scientists' best judgements will be subject to change.

\title{
Progressive thinking
}

\section{It is time to abandon GDP as the overriding measure of social development and economic health.}

n 1972, the tiny Himalayan nation of Bhutan opted to base its policy-making on indicators of 'gross national happiness', with King Jigme Singye Wangchuck declaring that this measure was more important than more conventional indicators such as gross domestic product (GDP). Today, after three decades and the biggest financial crisis since the Great Depression, his remarks seem prescient. A consensus among economists and policy-makers is growing that governments' reliance on GDP as the main proxy for social well-being and progress is leading the world in wrong and unsustainable directions.

As a measure of a country's overall economic activity, GDP is well-defined and fairly easy to calculate: it is simply the market value of all goods and services produced within a country's borders during a given year. It gives countries a convenient way to monitor their economic growth and their standing relative to other nations, and it correlates reasonably well with some measures of living standards.

But its simplicity has given GDP an outsized influence on many governments' economic decisions. The pursuit of economic growth as defined by an ever-rising GDP has become such a political imperative that any policy threatening to slow that rise has little chance of being adopted.

Yet GDP is known to be flawed as an indicator. For example, a developing country can accelerate its GDP growth by over-logging 